\title{
Las fundaciones de origen bancario italianas: Un espejo donde mirarnos
}

\author{
GLORIA PARDO AlÉS a , JULiÁN LÓPEZ MILLA a \\ a Universidad de Alicante, Instituto Interuniversitario de Economía Internacional, Campus de San \\ Vicente del Raspeig,Ap.99,03080Alicante,España.E-mail: gpardo@ua.es, j.lopez@ua.es
}

\begin{abstract}
RESUMEN
Este artículo estudia el nacimiento y la evolución de las fundaciones de origen bancario italianas y consta de tres partes. La primera está dedicada a la aparición de las fundaciones como resultado de la restructuración bancaria emprendida en 1990 mediante el denominado conferimento y a su evolución normativa. En la segunda se analizan aspectos tales como el mapa de fundaciones y la evolución de su patrimonio; su participación en el capital de las sociedades conferitarias; la rentabilidad de su patrimonio; sus cuentas de resultados; sus actividades institucionales y las inversiones relacionadas con el cumplimiento de su misión. El trabajo se cierra con unas conclusiones entre las que destacan dos: las fundaciones han contribuido positivamente a la reestructuración del mapa bancario italiano y a la estabilidad del sistema financiero durante la reciente crisis y, entre 2001 y 2012, han aportado 15.617 millones de euros a actividades propias de la economía social.
\end{abstract}

Palabras clave: Fundaciones de origen bancario, cajas de ahorros, economía social.

\section{The Italian Foundations of Banking Origin: A Mirror where we can see Ourselves}

\begin{abstract}
This paper examines the origin and development of Italian banking foundations and comprises three parts. The first is focused on the origin of these foundations, which is the result of the 1990 bank restructuring through the so-called conferimento (transfer) and its regulatory development. The second examines other issues such as the foundation map and the evolution of the foundations' assets; their shares in the capital of transferee corporations (società conferitaria); the profitability of their assets; their profit and loss accounts; their institutional activities; and the investments made to accomplish their mission. The study ends with a number of conclusions, of which we will highlight two: these foundations have made a positive contribution to restructuring the Italian banking map and the stability of the financial system during the recent crisis. Also, between 2001 and 2012, they have provided 15.617 million euros for activities specific to social economy.
\end{abstract}

Keywords: Foundations of Banking, Origin, Savings Banks, Social economy.

Clasificación JEL: G21, G23, L31

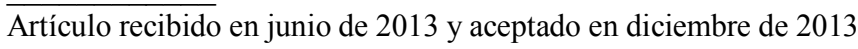

Artículo disponible en versión electrónica en la página www.revista-eea.net, ref. ə-32202 


\section{INTRODUCCIÓN}

Las cajas de ahorros españolas han experimentado una importante transformación durante los últimos años como consecuencia de la reestructuración del sector llevada a cabo para hacer frente a la crisis financiera. De un lado, han tenido lugar fusiones y absorciones entre entidades. De otro, se han realizado acuerdos para crear sistemas institucionales de protección (SIP) que han dado lugar al nacimiento de bancos a los que las cajas han transferido la totalidad de su negocio financiero ${ }^{1}$. El resultado de todo ello ha sido que de las 45 cajas de ahorros existentes en 2009 quedan en la actualidad 17 al tiempo que han surgido 19 fundaciones de carácter especial por transformación de otras tantas ${ }^{23}$. De las 17 cajas registradas, tan solo dos, las más pequeñas, ejercen la actividad crediticia de manera directa mientras que las otras lo hacen indirectamente a través de bancos, manteniendo la titularidad de la Obra Social. El negocio financiero de las antiguas cajas ha sido transferido a 11 bancos o grupos, 9 de los cuales han sido creados por los SIP y las cajas fusionadas mientras que los bancos BBVA y Sabadell han acabado integrando a Unnim y CAM, respectivamente ${ }^{4}$. Sin embargo, el proceso no puede darse aún por acabado puesto que tanto las fundaciones de carácter especial como las cajas de ahorros que en la actualidad ejercen la actividad crediticia indirectamente deberán transformarse en un futuro próximo bien en fundaciones bancarias, bien en fundaciones ordinarias, según cual sea su participación en la entidad de crédito a través de la cual operan ${ }^{5}$. Consiguientemente, en un breve plazo se habrá conformado en España un grupo de fundaciones cuya actividad estará orientada al desarrollo de la obra social y a

\footnotetext{
${ }^{1}$ Sobre las causas de la crisis de las cajas y su reforma, véase Martín y otros (2011).

${ }^{2} \mathrm{Al}$ cierre de este artículo en diciembre de 2013.

${ }^{3}$ La suma no es de 45 porque la transformación en fundaciones es posterior a los varios procesos de fusión que tuvieron lugar en 2010.

${ }^{4}$ Los diez grupos además de BBVA y Banco Sabadell son: Caixabank, Bankia, Kutxabank (que incluye a Banco Cajasur), Banco Mare Nostrum, Unicaja Banco (que incluye Banco CEISS), Catalunya Banc, Novagalicia Banco, Liberbank (que incluye banco Castilla La Mancha) y grupo Ibercaja que incluye (Banco Caja3 e Ibercaja Banco). Las cajas sobrevivientes son Caja de Onteniente y Colonya Caja Pollença.

${ }^{5}$ El proyecto de ley de cajas de ahorros y fundaciones bancarias a punto de ser promulgada obliga a las cajas de ahorros que ejerzan la actividad crediticia a través de un banco a transformarse en fundaciones bancarias cuando mantengan una participación igual o superior al 10 por ciento del capital o de los derechos de voto en el mismo o en fundaciones ordinarias si aquélla cayese por debajo de tal porcentaje. El plazo para la transformación es de un año para las cajas y de seis meses para las fundaciones de carácter especial desde la entrada en vigor de la ley (Proyecto de Ley de cajas de ahorros y fundaciones bancarias, Boletín oficial de las Cortes Generales, Senado, $\mathrm{n}^{\mathrm{o}} 260,7 / 11 / 2013$, págs. 37-71).
} 
la gestión, en su caso, de su participación en las entidades de crédito cesionarias 6 .

Las cajas de ahorros italianas experimentaron un proceso que guarda cierto paralelismo en la década de 1990. Se inició entonces el denominado conferimento: las cajas transfirieron su negocio bancario a sociedades por acciones reteniendo los fines benéfico-sociales originales y consolidándose posteriormente como fundaciones que han logrado un peso importante en el sector nonprofit italiano. Conocer la trayectoria de estas entidades puede contribuir a ampliar nuestra perspectiva sobre el potencial de las fundaciones de las cajas españolas.

Este artículo consta de tres partes. La primera versa sobre la creación de las Fundaciones de Origen Bancario (en adelante FOB) y sobre su evolución normativa. La segunda, basada en los informes anuales de la Associazione di fondazioni e di casse di risparmio spa (ACRI), se refiere a su actividad desde su nacimiento hasta 2011. En ella se analizan aspectos tales como el mapa de fundaciones y la evolución de su patrimonio; su participación en el capital de las sociedades por acciones receptoras del negocio financiero; la rentabilidad del patrimonio; sus cuentas de resultados; las actividades institucionales, sus características y localización; y las inversiones relacionadas con su misión. El trabajo se cierra con unas conclusiones.

\section{CREACIÓN Y EVOLUCIÓN NORMATIVA DE LAS FOB ITALIANAS}

Las FOB aparecieron como resultado del proceso de reestructuración de las instituciones de crédito de derecho público iniciado a finales de 1990. La banca pública tenía entonces un peso preponderante dentro del sistema bancario italiano, constituido por una gran cantidad de instituciones muy diversas tanto por su naturaleza jurídica como por su capacidad operativa. La reforma se acometió con el fin de atraer recursos propios, reducir su número e incrementar su tamaño medio a través de un proceso de fusiones y adquisiciones que las hiciera más competitivas en un mercado bancario europeo caracterizado por la libertad de establecimiento y por el modelo de banca universal ${ }^{7}$. La peculiar naturaleza

\footnotetext{
${ }^{6}$ Podemos conjeturar que incluso las fundaciones ordinarias, que podrán incluir en su nombre el de la caja originaria, tendrán como actividad principal, al menos inicialmente, la gestión de la obra social y, en su caso, la administración de su participación accionarial como principal fuente de ingresos.

${ }^{7}$ La Segunda Directiva de coordinación bancaria, de 15 de diciembre de 1989 (89/646) introduce el principio de la autorización comunitaria única. Una entidad de crédito autorizada en un Estado puede ejercer en toda la Comunidad el conjunto de actividades bancarias básicas, bien creando sucursales, bien prestando directamente sus servicios a partir del país en que esté esta-
} 
jurídica de las entidades crediticias públicas representaba un obstáculo para la consecución de estos objetivos en la medida en que dificultaba las operaciones de concentración y reestructuración y limitaba enormemente la posibilidad de captación de recursos propios en los mercados de capitales, de ahí que el propio Banco de Italia había identificado en el primer Libro Blanco de 1981 la conexión existente entre la naturaleza jurídica y el problema de recapitalización de estas entidades y defendido su transformación en sociedades anónimas en el segundo Libro Blanco publicado en $1988^{8}$.

Así pues, mediante la conocida como ley Amato $^{9}$ y el decreto que la desarrollaba fueron establecidos incentivos para que las entidades crediticias públicas $^{10}$ transfirieran su negocio financiero a una sociedad por acciones, manteniendo el ente transferente la gestión de las acciones recibidas a cambio y sus funciones originarias de asistencia a sectores sociales necesitados y fomento de actividades de interés público y utilidad social (investigación científica, educación, arte y sanidad). Se consideró de este modo que la sociedad por acciones era la forma jurídica idónea para el ejercicio de la actividad bancaria al ser más reconocible por los inversores y al facilitar la captación de nuevos capitales nacionales o extranjeros ${ }^{11}$.

Consiguientemente, 89 entidades realizaron el conferimento ${ }^{12}$, quedando obligadas a mantener el control directo o indirecto sobre la mayoría de las acciones con derecho de voto de la sociedad conferitaria o cesionaria. Por tanto, podemos afirmar que en esta primera etapa se produjo una privatización formal del negocio financiero al ser transferido a una sociedad anónima, pero no una privatización material del mismo dado que la participación mayoritaria debía permanecer en manos del ente conferente, de naturaleza pública ${ }^{13}$. Con el fin de garantizar el control mayoritario de la sociedad bancaria sin debilitar sus posibilidades de financiación, se obligó a los entes conferentes a constituir una reserva legal para la suscripción de los futuros aumentos de capital de la sociedad

blecido. El Estado miembro de origen se encarga del control global del establecimiento bancario y el Estado de acogida supervisa las sucursales establecidas en su territorio.

${ }^{8}$ Véase, De la Hucha, 1991.

${ }^{9}$ Legge 30 luglio 1990, n. 128 Disposizioni in materia di ristrutturazione e integrazione patrimoniale degli istituti de credito di diritto pubblico (Gazzeta Ufficiale n.182 del 6-8-1990). Decreto legislativo 20 de novembre 1990, n. 356. Disposizioni per la ristrutturazione e per la disciplina del grupo creditizio (Gazzeta Ufficiale n. 282 del 3-12-1990.

${ }^{10}$ Eran consideradas entidades crediticias públicas: istituti di crédito di diritto pubblico, casse di risparmio, casse comunale di crédito agrario y monti di crédito su pegno di seconda categoría.

${ }^{11}$ Una valoración del proceso de privatización de las cajas italianas puede encontrarse en Bisoni, C. y Cosma, S. (2001), Ayadi, R. (2009), Carletti E. y otros (2005).

${ }^{12}$ Más en concreto, 82 cajas de ahorros, 6 entidades de crédito de derecho público y 1 monte de piedad.

${ }^{13}$ Véase, De la Hucha, 1995. 
por acciones. A dicha reserva debían destinar al menos el $50 \%$ de los beneficios de las acciones y de las rentas derivadas del propio patrimonio ${ }^{14}$. La enajenación de acciones de la sociedad cesionaria estaba sometida a fuertes limitaciones y debía realizarse mediante oferta pública de venta para asegurar la transparencia del proceso. La pérdida del control mayoritario solamente podía producirse en casos excepcionales con el fin de reforzar el sistema crediticio italiano, su presencia internacional, su dimensión patrimonial o permitirle alcanzar una dimensión que aumentase su competitividad o por otras finalidades de interés público y requería informe del Banco de Italia y aprobación del Consejo de Ministros. Tras este interés subyacía la idea de que, al menos temporalmente, era necesario asegurar un cierto grado de continuidad respecto a la situación previa a la reestructuración, mientras que al mismo tiempo se evitaba que una venta apresurada pudiera favorecer la creación de posiciones dominantes o la adquisición de las entidades por parte de inversores extranjeros.

En 1994 -un año después de la promulgación del Testo Unico Bancario ${ }^{15}$ y coincidiendo con un período de privatizaciones-, se acometió la reforma de las entidades transferentes para que se orientaran exclusivamente al cumplimiento de los fines de interés general y utilidad social arriba citados, instándolas a diversificar el riesgo de inversión de su patrimonio y a reducir progresivamente la participación en la sociedad anónima salvaguardando el valor económico de su patrimonio $^{16}$. A cambio de un tratamiento fiscal favorable, se estableció un periodo de cinco años para que diversificaran su patrimonio de modo que, o bien los gastos necesarios para hacer frente a los fines quedaran cubiertos en un porcentaje superior al $50 \%$ con ingresos distintos de los derivados de la participación en la sociedad anónima, o bien que no más del $50 \%$ del propio patrimonio estuviera invertido en acciones de ésta. La directiva añadía que las entidades debían permanecer ajenas a la gestión de la sociedad anónima, limitándose a atender fines benéficos y de utilidad social con las rentas procedentes de su inversión. Se disipaba así cualquier duda sobre la posibilidad de que las nuevas entidades pudieran ejercer actividad crediticia de modo indirecto. La reforma favoreció un proceso de diversificación de la propiedad de las sociedades por acciones que permitió alcanzar un tamaño medio adecuado en el nuevo escenario bancario al tiempo que se mantenían las raíces territoriales de las entidades.

En 1998 se dio el paso definitivo para la separación entre fundación y socie-

\footnotetext{
${ }^{14}$ Véase, Rojo, 2003.

${ }^{15}$ Decreto legislativo 1 settembre 1993, n. 385, Testo unico delle leggi in materia bancaria e creditizia (GU n.230 del 30-9-1993 - Suppl. Ordinario n. 92 ). Entrada en vigor 1-1-1994.

${ }^{16}$ Legge 30 luglio 1994, n. 474. Conversione in legge, con modificazioni, del decreto-legge 31 maggio 1994, n. 332, recante norme per l'accelerazione delle procedure di dismissione di partecipazioni dello Stato e degli enti pubblici in societa' per azioni (Gazzetta Ufficiale n. 177 del 30-7-1994). Direttiva 18 novembre 1994, conocida como directiva Dini.
} 
dad por acciones ya que la entrada en vigor de la ley Ciampi y el decreto legislativo que la desarrollaba lograron: a) completar el proceso de restructuración estableciendo la obligación de las entidades transferentes de deshacerse del control de la sociedad transferida so pena de perder la categoría de entidad no comercial y las correspondientes ventajas fiscales; b) desarrollar el régimen civil y fiscal de las entidades transferentes, que a partir del decreto pasaron a ser llamadas fundaciones ${ }^{17}$. Tras sucesivas modificaciones, estas dos disposiciones constituyeron el cuerpo principal de regulación de las FOB, que desde entonces reúnen las características que se sistematizan a continuación ${ }^{18}$ :

1) Las FOB son personas jurídicas de naturaleza privada sin ánimo de lucro, dotadas de plena autonomía estatutaria y de gestión ${ }^{19}$. Persiguen exclusivamente fines de utilidad social y de promoción del desarrollo económico.

2) Desarrollan su actividad únicamente en los denominados sectores admitidos y operan de modo preferente en los llamados sectores relevantes que cada una haya elegido. Los sectores admitidos se agrupan en estas categorías ${ }^{20}$ :

a) Familia y valores conexos; desarrollo y formación juvenil; educación, instrucción y formación, incluyendo la adquisición de productos editoriales para la escuela; voluntariado, filantropía y beneficencia; religión y desarrollo espiritual; asistencia a los ancianos y derechos civiles.

b) Prevención de la criminalidad y seguridad pública; seguridad alimentaria y agricultura de calidad; desarrollo local y construcción popular local; protección de los consumidores; protección civil; salud pública, medicina preventiva y de rehabilitación; actividad deportiva; prevención y recuperación de las drogodependencias y patologías y trastornos psíquicos y mentales.

c) Investigación científica y tecnológica y protección y calidad ambiental.

d) Arte, actividad y bienes culturales.

${ }^{17}$ Hasta entonces las normas legales las nombraban como entidad transferente aunque desde el principio estaba claro su semejanza con las fundaciones y así lo había reconocido la doctrina.

${ }^{18}$ Legge 23 dicembre 1998, n.461 "Delega al Governo per il riordino della disciplina civilistica e fiscale degli enti conferenti..." Gazzetta Ufficiale n. 4 del 7 gennaio 1999. Decreto legislativo 17 maggio 1999, n. 153.

${ }^{19}$ La ley Ciampi zanja así el debate previo sobre la naturaleza pública o privada de estas instituciones.

${ }^{20}$ En la redacción original del Decreto legislativo 17 maggio 1999, $n .153$ solamente se decía que las fundaciones debían operar en al menos uno de los cuatro sectores relevantes (investigación científica; instrucción; arte, conservación y valoración de los bienes y de la actividad cultural y de los bienes ambientales; de la sanidad y de la asistencia a las categorías sociales débiles) al que debían destinar al menos el 50\% de sus rentas disponibles. La legge 28 de dicembre 2001 n. 448 amplía la lista tal como se presenta en el texto y distingue entre sectores admitidos y sectores relevantes, los tres de actuación preferente de cada fundación. 
e) Realización de obras públicas o de pública utilidad y de infraestructuras.

De entre los sectores admitidos, las fundaciones deben seleccionar cada tres años un número máximo de cinco en los que actuarán preferentemente (éstos son los denominados sectores relevantes) ${ }^{21}$. A ellos deben dedicar como mínimo el $50 \%$ de sus rentas netas.

3) Para la consecución de sus fines estatutarios, las fundaciones pueden operar bajo todas las modalidades compatibles con su propia naturaleza jurídica. Deben actuar con respeto al principio de economicidad de la gestión. Pueden asimismo ejercer su actividad a través de empresas, pero sólo si son instrumentales y para cumplir fines estatutarios en sectores relevantes. Es decir, las fundaciones no se ven obligadas a elegir entre el modelo dotacional (granting) de dar para hacer y el modelo funcional (operating) de hacer directamente.

4) A las FOB no les está permitido el ejercicio de funciones crediticias y se les prohíbe cualquier forma de financiación, de donación o de subvención, directa o indirecta, a entidades con ánimo de lucro o empresas de cualquier naturaleza, con excepción de las instrumentales, de las empresas sociales o de las cooperativas sociales.

5) Deben prever en sus propios estatutos que una quinceava parte (1/15) de sus ingresos netos se destine a crear un fondo especial en las regiones con el fin de establecer, a través de los entes locales, centros de servicio a disposición de las organizaciones de voluntariado, gestionados por ellas mismas con el fin de apoyar su actividad y cualificación.

6) Las fundaciones bancarias deben contar con órganos de gobierno diferenciados para realizar las funciones de dirección, administración y control.

a) Las competencias del órgano de dirección deben estar orientadas a la determinación de programas, prioridades y objetivos así como a la verificación de resultados. Entre éstas se encuentran la aprobación y modificación de los estatutos y del reglamento interno; el nombramiento y revocación de los componentes de los órganos de administración y control así como la determinación de sus remuneraciones; aprobación del balance; creación de empresas instrumentales; definición de las líneas generales de la gestión patrimonial y de la política de inversión y transformaciones y fusiones de las fundaciones.

En el órgano de dirección debe haber una representación prevalente y cualificada de entes públicos y privados representativos de la realidad local así como personalidades que por su profesionalidad, competencia y

${ }^{21}$ Este término, con este significado, fue introducido por la legge 28 de dicembre 2001 n. 448 que establecía que los sectores relevantes podían ser hasta tres como máximo. Esta cifra se elevó a cinco mediante decreto-legge 30 settembre 2003, $n$. 143. 
experiencia puedan contribuir eficazmente a la consecución de los fines institucionales de la fundación. Son los propios estatutos los que determinan el número idóneo de componentes del órgano de dirección así como la modalidad de designación y nombramiento, asegurando una composición equilibrada del mismo de forma que ninguna de las representaciones tenga participación mayoritaria. Además, ni los sujetos que tienen potestad para nombrar a los miembros del órgano de dirección ni los componentes de éste deben ser portadores de intereses ligados a los beneficiarios de las intervenciones de las fundaciones.

En el ejercicio de su autonomía estatutaria, las fundaciones de origen asociativo $^{22}$ pueden mantener la asamblea de socios y que ésta designe una parte no mayoritaria de los componentes del órgano de dirección.

b) El órgano de administración es el encargado de la gestión de la fundación. Le competen todos los poderes de administración ordinaria y extraordinaria en el ámbito de programas, prioridades y objetivos decididos por el órgano de dirección que no estén reservados a éste por ley.

c) El órgano de control está compuesto por personas que reúnen requisitos profesionales para el ejercicio del control legal de las cuentas.

d) En las FOB cuya actividad se dirija por mandato estatutario a un concreto ámbito territorial, los órganos colegiados deben contar con una representación no inferior al $50 \%$ de personas residentes en el mismo durante un período mínimo de tres años.

e) En cuanto a las personas que ocupan cargos en los órganos de dirección, administración y control, deben reunir los requisitos de profesionalidad y honorabilidad; son nombrados por un período determinado sin que pueda prorrogarse; deben ser independientes y no pueden desempeñar funciones de administración, dirección o control en la sociedad bancaria a la que se transfirió el negocio crediticio o en sus controladas o participadas.

7) El patrimonio de las FOB está vinculado a sus fines estatutarios y debe ser gestionado sin ánimo de lucro, según los principios de transparencia y moralidad. Las FOB deben invertir el patrimonio procurando la diversificación del riesgo y la obtención de un rendimiento adecuado asegurando con ello el cumplimiento de sus fines, especialmente el desarrollo del territorio. La gestión del patrimonio debe desarrollarse bajo modalidades organizativas internas idóneas para asegurar la separación de las actividades de las FOB o bien puede ser confiada a intermediarios habilitados. El patrimonio se in-

\footnotetext{
${ }^{22}$ Las fundaciones de origen asociativo son aquéllas originadas por las cajas de ahorro cuyo fondo de dotación inicial fue constituido íntegramente por contribuciones de ciudadanos privados. En la actualidad, 31 fundaciones mantienen este órgano.
} 
crementa con la reserva obligatoria $^{23}$ fijada por la Autoridad de Vigilancia ${ }^{24}$ así como con las plusvalías y minusvalías relativas a las participaciones en la sociedad a la que se transfirió el negocio financiero.

8) Las FOB solo pueden tener participaciones de control ${ }^{25}$ en sociedades instrumentales, o sea, empresas que operan exclusivamente para la realización directa de los fines estatutarios perseguidos por la fundación en los sectores relevantes.

La ley Ciampi obligó a las fundaciones a reducir su participación en las sociedades bancarias cesionarias por debajo del nivel de control en un plazo de cuatro años a partir de su entrada en vigor que posteriormente se alargó hasta el 31 de diciembre de $2005^{26}$. La venta de las acciones se incentivó mediante la exención fiscal de las plusvalías correspondientes, siempre que la operación se llevara a cabo dentro del plazo establecido.

Asimismo, también les impuso la reducción de sus participaciones en empresas distintas de las consideradas instrumentales por debajo del nivel de control, estableciéndose para ello los mismos plazos que en el caso anterior.

Sin embargo, a partir de 2003 se estableció un trato excepcional para las fundaciones más pequeñas, con patrimonio neto no superior a 200 millones de euros, o que operan preferentemente en regiones de estatuto especial ${ }^{27}$, de manera que éstas sí pueden mantener la participación de control en las sociedades por acciones cesionarias ${ }^{28}$.

9) Pueden mantener participaciones en sociedades no instrumentales siempre que no sean de control. Pueden invertir una cuota no superior al $15 \%$ del patrimonio propio en bienes inmuebles distintos de los instrumentales ${ }^{29}$.

${ }^{23}$ La reserva obligatoria es aprobada anualmente y en la actualidad es el $20 \%$ del resultado económico de la fundación.

${ }^{24}$ Está prevista la creación de una Autoridad de Vigilancia en el marco de una reforma del Código Civil italiano. Hasta entonces cumple sus funciones el Ministerio de economía y finanzas; Pero incluso después corresponderá a dicho Ministerio la supervisión de las FOB que mantengan una participación de control sobre la sociedad por acciones cesionaria.

${ }^{25}$ Participación de control: la que permite disponer de la mayoría de votos en la asamblea ordinaria o la que permite ejercer una influencia dominante en la misma. Decreto legislativo 17 maggio 1999, $n .153$, art. 6.2.

${ }^{26}$ El plazo se alargó para compensar la paralización de las operaciones de venta como consecuencia del expediente abierto por la Comisión Europea para verificar si las ayudas eran compatibles con la libertad de mercado. La Comisión resolvió a favor de las fundaciones en agosto de 2002.

${ }^{27}$ Son regiones con estatuto especial: Sicilia, Cerdeña, Valle de Aosta, Trentino-Alto Adigio y Friuli-Venecia Julia.

${ }^{28}$ Decreto legge 24 giugno 2003 n. 143 (Gazzetta Ufficiale $n 185$ del 11.08.2003).

${ }^{29}$ El Decreto legge 24 giugno $2003 n .143$ en su artículo $4^{\circ}$ permite a las FOB invertir en bienes inmuebles no instrumentales hasta el $10 \%$ del patrimonio. Este porcentaje ha sido elevado al 
Asimismo les está permitido emplear parte de su patrimonio en bienes muebles o inmuebles que aunque no produzcan una adecuada rentabilidad tengan interés histórico o artístico con destino público permanente o estén destinados a sede de las fundaciones o al desarrollo de su actividad institucional o a la de las empresas instrumentales.

10) Las FOB deben aplicar sus rentas a las siguientes partidas y por este orden: a) gastos de funcionamiento; b) gastos fiscales; c) reservas obligatorias; d) a los sectores relevantes, al menos el 50\% de los ingresos restantes o el porcentaje establecido por la Autoridad de Vigilancia si es mayor; e) otros fines estatutarios, reinversión o reservas voluntarias; f) adquisición, a demanda de los centros educativos, de productos editoriales para los colegios públicos y privados en el ámbito territorial en el que operen con el compromiso de que sean utilizados para fomento de la lectura entre los estudiantes y también para favorecer la lectura de la prensa diaria en las escuelas.

11) Finalmente, está prohibido a las FOB repartir o asignar a los asociados, administradores, fundadores o subalternos participación en los beneficios, en el patrimonio o en cualquier otra forma de remuneración diferente de las compensaciones, indemnizaciones o retribuciones previstas. Son entidades non for profit en las que se compatibiliza el ejercicio de una actividad económica por sujetos en los que está ausente el ánimo de lucro.

12) Corresponde a la Autoridad de Vigilancia determinar anualmente el importe de las dotaciones a reservas. La dotación anual al fondo de reserva obligatoria es del $20 \%$ del resultado del ejercicio. La dotación anual a las reservas voluntarias para conservar el valor del patrimonio es como máximo del 15 $\%$ del resultado del ejercicio ${ }^{30}$. Ambos porcentajes permanecen estables desde 2001.

13) En la actualidad se atribuye a la Autoridad de Vigilancia, la supervisión de las fundaciones con el fin de objeto verificar que las fundaciones operan con respeto a la ley y a los estatutos, que gestionan prudentemente el patrimonio para obtener una rentabilidad adecuada y tutelar los diversos intereses contemplados en los estatutos.

Entre otras funciones, la Autoridad de Vigilancia autoriza las fusiones entre fundaciones; determina anualmente el límite mínimo de renta en relación con el patrimonio compatible con una gestión prudente del riesgo adecuada

$15 \%$ por el decreto legislativo $\mathrm{n}^{\circ} 78$ de 31 de mayo de 2010. En plena crisis financiera, esta medida puede interpretarse no solo como una flexibilización de las posibilidades de inversión de las fundaciones, sino también como una forma de apoyar al sector inmobiliario.

${ }^{30}$ En caso de que en ejercicios previos haya habido pérdidas, el resultado del ejercicio se computa neto del importe del $25 \%$ destinado a la cobertura de dichas pérdidas. No podrían dotarse reservas voluntarias si las pérdidas de ejercicios anteriores no estuvieran íntegramente cubiertas. 
a la inversión patrimonial de las fundaciones; aprueba las modificaciones estatutarias; puede suspender a los órganos de administración y control de las fundaciones en caso de graves irregularidades en la gestión o graves incumplimientos de las disposiciones legislativas, administrativas y estatutarias nombrando comisarios extraordinarios para realizar sus funciones y, llegado el caso, puede incluso disponer la liquidación de la fundación. Por último, anualmente debe presentar al parlamento un informe sobre la actividad desarrollada por las $\mathrm{FOB}^{31}$.

14) En cuanto al régimen tributario, las FOB son consideradas entidades no comerciales $^{32}$ incluso aunque persigan sus objetivos mediante empresas instrumentales ${ }^{33}$. Además gozan de ciertas ventajas fiscales: los dividendos percibidos no están sujetos a impuestos; las transmisiones a favor de las fundaciones bancarias no están sujetas al impuesto sobre sucesiones y donaciones; están exentas del impuesto municipal sobre el incremento del valor de los bienes inmuebles adquiridos a título gratuito; no se les aplica el impuesto sustitutivo del municipal sobre el incremento del valor de los bienes inmuebles.

\section{EVOLUCIÓN Y ACTIVIDADES DE LAS FOB DESDE SU CREACIÓN}

\subsection{Número y evolución de su patrimonio}

Las fundaciones resultantes del proceso de reestructuración bancaria alcanzaron el número de $89^{34}$. Tras la fusión de dos de ellas en 2004 su número quedó reducido a 88 , manteniéndose estable desde entonces.

Siempre ha existido un elevado grado de concentración patrimonial y territorial de las FOB derivado del mapa originario de cajas de ahorro y que sin duda tiene sus raíces históricas en las grandes diferencias de renta por persona y ahorro entre el Norte, Centro y Mezzogiorno italianos. Según los últimos datos disponibles correspondientes a 2012, Cariplo ${ }^{35}$, la fundación de mayor tamaño, cuenta con un patrimonio de más de 6.500 millones de euros, que representa el $15.5 \%$ del total del sistema. Las cinco fundaciones más grandes controlan el

\footnotetext{
${ }^{31}$ Decreto-legge 31 maggio 2010, n. 78, art. 52.

${ }^{32}$ Artículo 87.1.c del TUIR, Testo Único delle Imposte sui Redditi, aprobado mediante decreto del Presidente de la República nº 917 de 22 de diciembre de 1986.

${ }^{33}$ Hasta 2004 gozaron de una reducción del $50 \%$ del impuesto sobre la renta de las personas jurídicas. Decreto del Presidente della Repubblica 29 settembre 1973, $n$. 601. Disciplina delle agevolazioni tributarie. (Gazetta Ufficiale n.268 del 16-10-1973 - Suppl. Ordinario ).

${ }^{34} 82$ nacieron de cajas de ahorros, 6 de institutos de crédito de derecho público y una de un monte de piedad de segunda categoría.

${ }^{35}$ Fondazione Cassa di Risparmio delle Provincie Lombarde.
} 
43,8 \% del patrimonio. Las 18 grandes que componen el primer quintil suman el $73,6 \%$ mientras que las 18 del último quintil, las más pequeñas, poseen sólo el $1,6 \%$ (ACRI, 2013).

Figura 1

Distribución geográfica de las fundaciones bancarias italianas

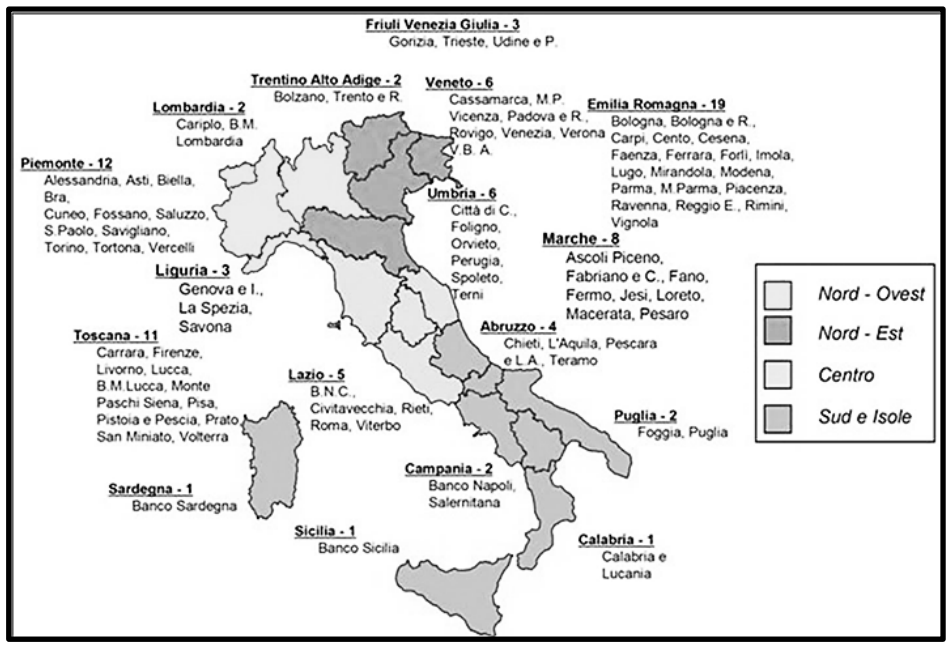

Fuente: ACRI.

Como puede observarse en el mapa, 47 de las 88 fundaciones tienen su sede en el norte de Italia; 30 en el centro y sólo 11 en el sur y en las islas. Si nos referimos al tamaño según su patrimonio (Tabla 1), las fundaciones del noroeste son las de mayor tamaño medio (1.107 millones de euros), casi el triple del tamaño de las del nordeste o del centro. En el noroeste se ubican además 6 de las 18 más grandes. En el sur del país e islas predominan por el contrario las más pequeñas, con un tamaño medio de 181 millones de euros ${ }^{36}$.

Pese a la existencia de fundaciones con dimensiones muy dispares, podemos decir que en términos generales su patrimonio neto medio se ha incrementado constantemente en todas las divisiones geográficas y en todos los tamaños (quintiles) si bien en el caso de las fundaciones pequeñas a un ritmo más lento que el resto. Aun así, como consecuencia de la crisis financiera actual, el crecimiento se ha ralentizado y para algunas agrupaciones estancado a partir del año

${ }^{36}$ La consecuencia de la concentración territorial y patrimonial de las fundaciones es una menor actividad institucional en el sur de Italia. Para compensar ese desequilibrio las fundaciones suscribieron a finales de 2005 un acuerdo con el mundo del voluntariado y otros actores del tercer sector para constituir la Fondazione per il Sud que comenzó a operar en enero de 2007 en las regiones meridionales. Además, se ha suscrito un acuerdo de intenciones para el periodo 2010-2014 con el fin de prolongar el apoyo a esta fundación. 
2008, aunque sigue mostrando tasas positivas en el año 2010 y no es hasta los últimos dos años cuando observamos una caída pronunciada del patrimonio medio que se refleja en todos los grupos, tanto por tamaño como por localización geográfica.

Tabla 1

Distribución del patrimonio de las FOB según su dimensión y el área geográfica de origen (a)

\begin{tabular}{|c|c|c|c|c|c|c|c|c|c|c|c|c|c|}
\hline \multirow{2}{*}{$\begin{array}{l}2012 \\
\text { Zona }\end{array}$} & \multicolumn{2}{|c|}{ Pequeñas } & \multicolumn{2}{|c|}{$\begin{array}{l}\text { Medianas- } \\
\text { pequeñas }\end{array}$} & \multicolumn{2}{|c|}{ Medianas } & \multicolumn{2}{|c|}{$\begin{array}{l}\text { Medianas- } \\
\text { grandes }\end{array}$} & \multicolumn{2}{|c|}{ Grandes } & \multicolumn{2}{|c|}{ Total } & \multirow{2}{*}{$\frac{\text { Media }}{\text { M€ }}$} \\
\hline & $M €$ & $\mathbf{N}^{0}$ & $M €$ & $\mathbf{N}^{\circ}$ & M€ & $\mathbf{N}^{\circ}$ & $M €$ & $\mathrm{~N}^{\circ}$ & $M €$ & $\mathrm{~N}^{\circ}$ & $\mathbf{M €}$ & $\mathbf{N}^{\circ}$ & \\
\hline Noroeste & 155 & 4 & 112 & 1 & 584 & 3 & 750 & 3 & 17224 & 6 & 18825 & 17 & 1107 \\
\hline Nordeste & 118 & 5 & 450 & 4 & 965 & 6 & 2723 & 8 & 8419 & 7 & 12675 & 30 & 423 \\
\hline Centro & 337 & 7 & 636 & 7 & 1195 & 7 & 1971 & 5 & 4559 & 4 & 8698 & 30 & 290 \\
\hline Sur, islas & 72 & 2 & 528 & 5 & 300 & 2 & 210 & 1 & 875 & 1 & 1985 & 11 & 181 \\
\hline Total & 682 & 18 & 1726 & 17 & 3044 & 18 & 5654 & 17 & 31077 & 18 & 42183 & 88 & 479 \\
\hline Media & \multicolumn{2}{|c|}{38} & \multicolumn{2}{|c|}{102} & \multicolumn{2}{|c|}{169} & \multicolumn{2}{|c|}{333} & \multicolumn{2}{|c|}{1727} & \multicolumn{2}{|c|}{479} & \\
\hline
\end{tabular}

Nota: M€ significa millones de euros.

(a): A 31 de diciembre de cada año.

Fuente: ACRI, Rapporto Annuale, varios años.

Figura 2

Evolución del patrimonio neto de las FOB Millones de euros

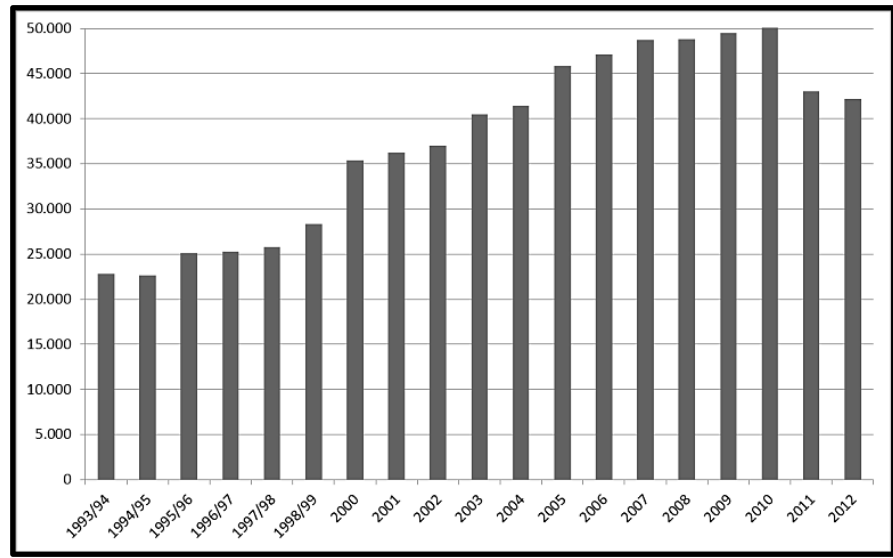

A partir del año 2000 los datos corresponden a 31 de diciembre de cada año.

Fuente: Elaboración propia a partir de ACRI, Rapporto Annuale, varios números.

La Figura 2 muestra el proceso de consolidación del sistema fundaciones a través de la evolución de su patrimonio neto desde su creación. Puede observarse que éste se ha duplicado en 17 años, alcanzando los 50.000 millones de euros en 2010. Durante los años previos a la crisis (2000-2007), su crecimiento 
fue muy vigoroso, alcanzando una tasa anual acumulativa media del 4,68 \%, e incluso puede decirse que soportó relativamente bien los primeros embates de la crisis financiera pues continuó mostrando ritmos de crecimiento positivos del $0,95 \%$ en el periodo 2008-2010. Sin embargo, las cuentas de 2011 reflejan una importante caída de ese patrimonio por valor de 7 mil millones euros aproximadamente, lo cual representa un 14,21 \% respecto al año anterior. Esta reducción tiene su origen principalmente en la exigencia de adecuar los valores de las participaciones accionariales a la evolución de los mercados financieros en los últimos años, lo que ha castigado fuertemente a los valores cotizados.

\subsection{Participación de las FOB en el capital de las entidades cesionarias}

En el activo del sistema FOB, el inmovilizado material e inmaterial representa tan solo una pequeña proporción inferior al $4 \%$. El resto son activos financieros a distintos plazos y disponibilidades líquidas. Hay que tener presente que las fundaciones no son meras inversoras ocasionales. Al contrario, se trata de inversoras institucionales con un horizonte temporal amplio, preocupadas tanto por su solidez patrimonial como por obtener una rentabilidad adecuada a largo plazo. Entre las inversiones financieras de las FOB, la participación en las entidades cesionarias de su actividad crediticia tiene un peso muy relevante que ha evolucionado a lo largo del tiempo en el contexto de un conjunto normativo cambiante y a veces contradictorio, como se ha explicado anteriormente.

Efectivamente, la presencia de las FOB en el capital de las citadas entidades receptoras ha ido disminuyendo con el paso del tiempo. Inicialmente, la Ley Amato $^{37}$ las obligaba a mantener una participación de control en las mismas como se observa en la Tabla 2, ésta era la situación en 1990-. Dicha obligación quedó derogada en 1994 por la Ley 474 al tiempo que la directiva $\operatorname{Dini}^{38}$ promovía la diversificación mediante incentivos fiscales de las inversiones patrimoniales introduciendo un límite del $50 \%$ en el peso de las participaciones bancarias sobre el patrimonio de las fundaciones, de manera que un año más tarde eran 62 las FOB con participaciones en la cesionaria inferiores al 50\% e incluso una de ellas se había deshecho de todas sus acciones.

Sin embargo, en 1998, todavía 47 de las 89 fundaciones mantenían porcentajes superiores al $50 \%$. Se adopta entonces un cambio de enfoque con la ley Ciampi ${ }^{39}$ que obliga a las FOB a deshacerse de sus participaciones de control. La transmisión de las acciones se produjo a un buen ritmo entre 1994 y 2000 pero sufrió un parón en los años 2001 y 2002 como consecuencia de la decisión de la Comisión Europea de suspender la concesión de ventajas fiscales previstas

\footnotetext{
${ }^{37}$ Legge 30 luglio 1990, n. 128. Decreto Legislativo20 novembre 1990, n.356.

${ }^{38}$ Legge 30 luglio 1994, n. 474. Direttiva 18 novembre 1994.

${ }^{39}$ Legge 23 dicembre 1998, n.461. Decreto legislativo 17 maggio 1999, n. 153.
} 
en la ley para estas operaciones por si pudieran constituir ayuda de estado que contraviniera el principio de libre mercado. Finalmente, en agosto de 2002 la resolución fue favorable a las fundaciones. En 2003, todas las fundaciones, salvo aquéllas para las que se reguló una excepción (las 15 poseedoras de patrimonio neto inferior a 200 millones de euros o con sede en regiones con estatuto especial), habían reducido sus participaciones en la banca cesionaria por debajo del $50 \%$ e incluso un número significativo de ellas ya no conservaba acciones en ella. Al acabar 2012, de las 53 fundaciones con participaciones inferiores al $50 \%, 22$ mantenían una participación inferior al $5 \%, 17$ se situaban entre el $5 \%$ y el $20 \%$, mientras que las participaciones de las otras 14 estaban entre el 20 y el $50 \%$.Cabe también hacer hincapié en que las fundaciones que mantienen un control mayoritario sobre las sociedades por acciones cesionarias son las más pequeñas y por tanto representan una parte muy reducida del patrimonio total de las fundaciones y que los bancos cuya propiedad controlan son igualmente pequeños y con muy poco peso dentro del sistema bancario italiano. Sin embargo, tanto unas como otros están muy enraizados en el territorio y realizan una labor dinamizadora de la economía muy vinculada a la realidad local en la que operan.

\section{Tabla 2}

Participación de las FOB en el capital sociedades cesionarias. Número de fundaciones

\begin{tabular}{|l|r|r|r|r|r|r|r|r|r|r|r|}
\hline & $\mathbf{1 9 9 0}$ & $\mathbf{1 9 9 5}$ & $\mathbf{1 9 9 8}$ & $\mathbf{2 0 0 0}$ & $\mathbf{2 0 0 2}$ & $\mathbf{2 0 0 3}$ & $\mathbf{2 0 0 4}$ & $\mathbf{2 0 0 6}$ & $\mathbf{2 0 0 8}$ & $\mathbf{2 0 1 0}$ & $\mathbf{2 0 1 2}$ \\
\hline Participación $>50 \%$ & 88 & 62 & 47 & 23 & 20 & 15 & 16 & 15 & 15 & 15 & 13 \\
\hline Participación $\leq 50 \%$ & 0 & 26 & 36 & 57 & 59 & 63 & 58 & 56 & 55 & 55 & 53 \\
\hline Sin participación & 0 & 1 & 6 & 9 & 10 & 11 & 14 & 17 & 18 & 18 & 22 \\
\hline Total & 88 & 89 & 89 & 89 & 89 & 89 & 88 & 88 & 88 & 88 & 88 \\
\hline
\end{tabular}

De 2002 a 2009 los datos son a 21 de septiembre.

Fuente: ACRI, Informe Anual, varios números.

Desde su creación, las FOB han contribuido de manera significativa a la reorganización del sistema crediticio italiano y al nacimiento de los grandes grupos bancarios del país como Intesa San Paolo, Unicredit y Monte dei Paschi di Siena. Merece la pena destacar en este sentido el papel que han jugado desde el inicio de la crisis financiera internacional en 2007 como accionistas de las sociedades a las que transfirieron en su día el negocio bancario. Después de que la ley Ciampi les prohibiera mantener el control de esas sociedades, las participaciones se redujeron en términos absolutos y relativos alcanzando un mínimo en 2006 (Figura 3). Concretamente, las FOB tenían en el año 2000 participaciones en la sociedad cesionaria por valor 17.000 millones que representaban el 43,8 \% del activo y en 2006 la participación había caído a 13.700 millones de euros o un 25,1 \% del activo; desde ese mínimo relativo hasta el año 2010 la participación en las conferitarias se ha incrementado por valor de 12.000 millones de euros alcanzando un peso en el activo de $42,5 \%$ similar al de principios de si- 
glo. Simultáneamente, las inversiones en instrumentos financieros se han reducido en 8.000 millones de euros y las participaciones en otras sociedades han perdido 5.000 mil millones desde su máximo en 2008. En 2012, tras los ajustes del valor de las acciones la participación en la cesionaria es de casi un $40 \%$, unos 15 puntos más que en $2006^{40}$. Esta actuación ha significado una importante contribución al reforzamiento de la solvencia de las entidades, al cumplimiento de los nuevos requerimientos del acuerdo de Basilea III y, por ende, a la estabilidad del sistema bancario italiano, que hasta la fecha no ha precisado ayudas públicas tan cuantiosas como en otros países europeos ${ }^{41}$.

Figura 3

Estructura del activo de las FOB

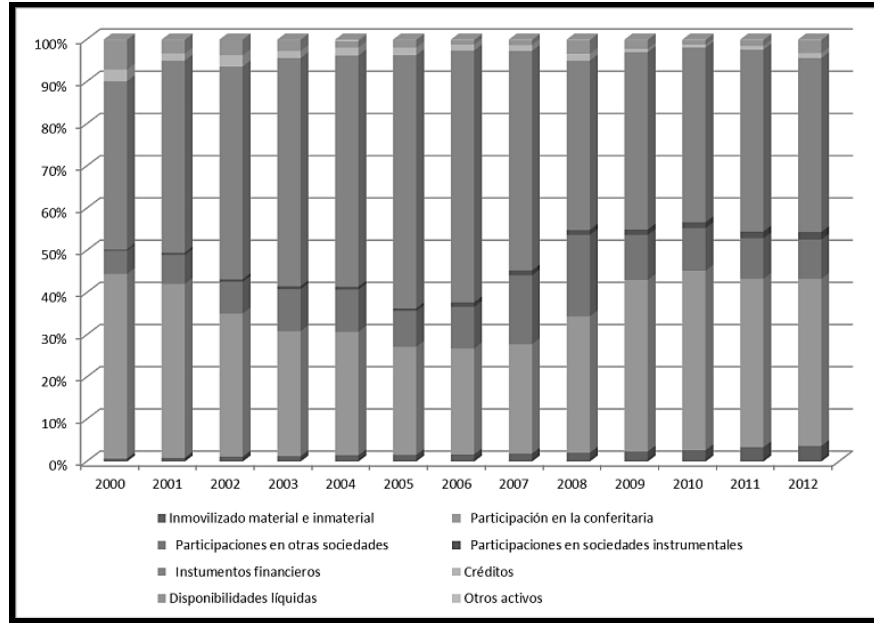

Fuente: Elaboración propia a partir de datos de ACRI, Rapporto annuale, Varios años.

\subsection{Las fuentes de ingresos de las fundaciones y su aplicación}

Las fuentes principales de ingresos de las fundaciones son los dividendos que reciben de la sociedad bancaria cesionaria, seguidos de los resultados de las inversiones financieras (Tabla 3).

${ }^{40}$ A lo largo de 2012, 20 FOB han suscrito aumentos de capital por valor de 1.194,7 millones de euros. Desde el inicio de la crisis financiera internacional en 2008 hasta 2012 las FOB han puesto a disposición de los principales bancos nacionales cerca de 8,6 millardos de euros, 7,5 millardos en aumentos de capital y 1,5 millardos en obligaciones convertibles. (ACRI, 2013).

${ }^{41}$ Así lo ha reconocido el gobernador del Banco de Italia cuando con ocasión de la Jornada Mundial del Ahorro de 2009 manifestó que "las fundaciones han sido un ancla para la banca italiana. Le han acompañado incluso en la fase más tempestuosa de la crisis financiera en el reforzamiento patrimonial" (ACRI, 2010). 
Tabla 3

Composición porcentual de los ingresos por origen

\begin{tabular}{|c|c|c|c|c|c|c|c|c|c|c|c|c|}
\hline Tipo de ingreso & 2001 & 2002 & 2003 & 2004 & 2005 & 2006 & 2007 & 2008 & $2009^{*}$ & 2010 & 2011 & 2012 \\
\hline Dividendos de la SpA cesionaria & 57 & 64,4 & 42,8 & 41,6 & 38,7 & 36,7 & 51,4 & 78,5 & 24,4 & 35,6 & 54,7 & 29,1 \\
\hline Otros ingresos & 43 & 35,6 & 57,2 & 58,4 & 61,3 & 63,3 & 48,6 & 21,5 & 75,6 & 64,4 & 45,3 & 70,9 \\
\hline Gestión del patrimonio & 1 & $-0,9$ & 15 & 16,5 & 13,9 & 9,6 & 9,5 & $-6,5$ & 18,9 & 18,1 & 1,5 & 26,1 \\
\hline - Dividendos de otras participaciones & 11,2 & 8,4 & 8,7 & 8,1 & 11,3 & 17,3 & 15,1 & 21,8 & 10 & 12,4 & 34,5 & 20 \\
\hline $\begin{array}{l}\text { Resultados de las inversiones } \\
\text { financieras }\end{array}$ & 24,5 & 17,6 & 28,1 & 25,6 & 28,7 & 28,9 & 20,1 & $-5,7$ & 37,9 & 24,2 & $\begin{array}{c}- \\
43,5\end{array}$ & 6,9 \\
\hline $\begin{array}{l}\text { Otros ingresos ordinarios y } \\
\text { extraordinarios }\end{array}$ & 6,3 & 10,5 & 5,4 & 8,2 & 7,4 & 7,5 & 3,9 & 11,9 & 8,8 & 9,7 & 52,8 & 17,9 \\
\hline Total & 100 & 100 & 100 & 100 & 100 & 100 & 100 & 100 & 100 & 100 & 100 & 100 \\
\hline
\end{tabular}

${ }^{(*)}$ El pago de dividendos en acciones se incluye en "dividendos de la conferitaria". Si tales dividendos se incluyeran en la rúbrica de "otros ingresos ordinarios y extraordinarios", los índices serian del 17,8 \% y 15,4\%.

Fuente: ACRI: Informe Anual, varios años.

La progresiva reducción de la participación en el capital de las sociedades cesionarias a la que acabamos de referirnos ha tenido un reflejo lógico en la partida de dividendos, que también ha marcado su mínimo en 2006, aunque es preciso señalar que su monto total es producto no sólo del porcentaje de participación sino también de la política de distribución de dividendos de esas sociedades. En 2009, en plena crisis financiera, esta rúbrica sufrió una drástica caída causada en parte por el hecho de que Intesa San Paolo no distribuyó dividendos; porque Unicredit procedió a una ampliación de capital gratuita en vez de entregar dividendos en efectivo y Monte dei Paschi di Siena pagó un dividendo equivalente a una sexta parte del distribuido en 2008. En años siguientes se produjo una recuperación de la partida como consecuencia tanto de los mayores dividendos ingresados como del incremento de la participación en las sociedades por acciones a que hemos hecho referencia en el apartado anterior. En cuanto a la partida de otras inversiones financieras, cabe destacar que perdió peso en 2010 por el descenso generalizado de los tipos de interés a lo que se ha añadido las minusvalías sufridas en el último año.

El sistema fundaciones ha obtenido una rentabilidad patrimonial positiva y creciente desde su fundación, alcanzando un máximo del $8 \%$ en 2007. También ha soportado de modo satisfactorio la inestabilidad financiera de los últimos años, si bien la intensa volatilidad de los mercados en la segunda mitad de 2011 ha provocado una disminución notable de la misma, aunque se ha mantenido en niveles claramente positivos que alcanzan el 3,6 \% en 2012.

El resultado económico del sistema FOB se obtiene restando a los ingresos totales (gestión patrimonial, dividendos e intereses, operaciones financieras y de las empresas instrumentales, otros ingresos ordinarios y extraordinarios) los gastos de funcionamiento y gestión de las inversiones y los impuestos. Dicho resultado a su vez se distribuye entre dotaciones a reservas (obligatorias y para 
la integridad del patrimonio) ${ }^{42}$ y fondos destinados a la actividad institucional. Con cargo a éstos últimos se dota también un fondo de estabilización que permite amortiguar el impacto del ciclo económico sobre los fondos disponibles para las actuaciones anuales de las FOB. Así pues, los fondos para actividades institucionales no forman parte de la cuenta de resultados, sino que son aplicación de los resultados obtenidos por la fundación, procedentes de la inversión de su patrimonio.

La Figura 4 muestra la evolución de las rúbricas más significativas de la cuenta de resultados en términos de patrimonio total medio. Si comparamos la evolución de las reservas y los fondos destinados a las actividades institucionales en términos de patrimonio medio, se observa que en los primeros ejercicios, gran parte de los limitados beneficios obtenidos se destinaban a la constitución de reservas que, como vimos en la primera parte, debían ser suficientes para suscribir posibles ampliaciones de capital de las sociedades por acciones receptoras. Las fundaciones fueron liberadas posteriormente de esa obligación y ello hizo que ganara peso la proporción destinada a sus fines benéfico-sociales.

Figura 4

Principales rúbricas de la cuenta de resultados de las FOB en porcentaje sobre el patrimonio neto

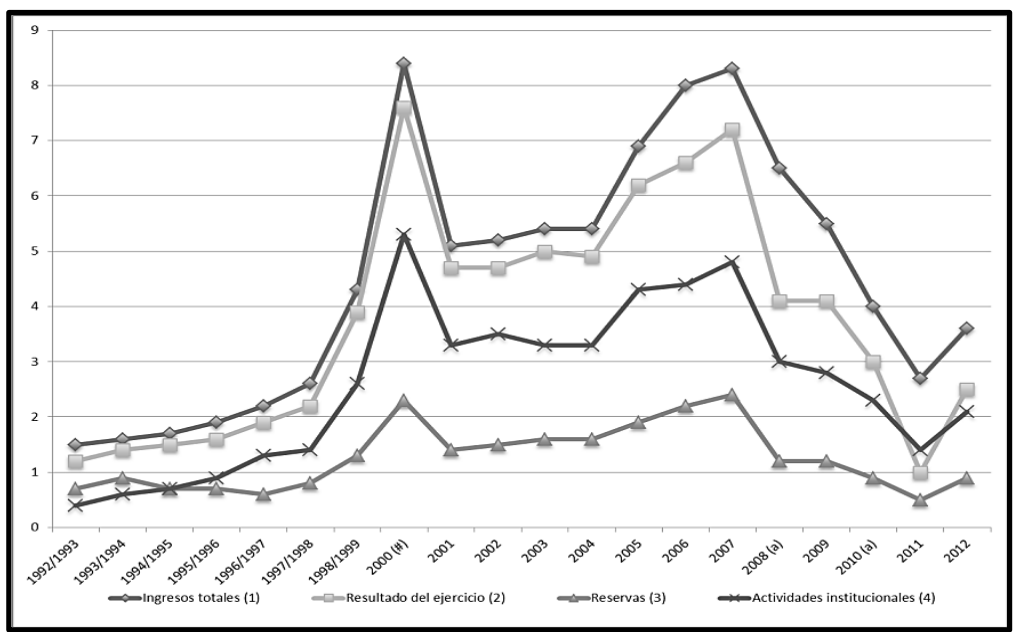

(\#): La duración de este ejercicio superó los doce meses, como consecuencia de una nueva definición de los períodos contables. (1): Ingresos ordinarios y extraordinarios. (3): Incluye reservas voluntarias y obligatorias. (4): Fondos para la promoción del voluntariado y para el desarrollo de los fines propios de la fundación.

Fuente: (ACRI, 2012).

${ }^{42}$ La dotación al fondo de reservas obligatorias se fija anualmente y es del $20 \%$ del resultado de gestión. La dotación al fondo de reserva para la integridad del patrimonio es voluntaria y como máximo del $15 \%$ del resultado de la gestión. 
Hasta el año 2007, todas las variables mantuvieron una tendencia creciente, pero no al mismo ritmo ya que, mientras que el resultado sobre el patrimonio se multiplicó por seis, los fondos dedicados a la actividad institucional lo hicieron por doce pero los dedicados a reservas tan solo se cuadruplicaron. A partir de 2008, las cuatro variables descendieron como consecuencia de la crisis financiera internacional, aunque puede apreciarse que la fuerte caída del resultado se trasladó en mayor medida a las reservas que a los fondos asignados a la actividad institucional. Durante los últimos años, las fundaciones han priorizado la actividad institucional modulando las reservas con el fin de mantener su presencia activa en los territorios de referencia. En el último año se observa una modesta recuperación en todos los indicadores, aunque permanecen en niveles muy inferiores a los previos a la crisis.

\subsection{Actividades institucionales de las FOB}

Analizaremos ahora la evolución del montante de los fondos dedicados por las FOB a sus actividades y su distribución entre los sectores admitidos.

La Figura 5 muestra la evolución del importe total distribuido a lo largo de la última década. Se aprecia un crecimiento muy vigoroso de los fondos inyectados hasta 2007, año en que se alcanzó el máximo absoluto con la cantidad de $1.751,1$ millones de euros. Durante esos años previos a la crisis los fondos donados crecieron a una tasa anual acumulativa media del 10\%. Sin embargo, la crisis financiera internacional ha golpeado también a las FOB y a pesar de la existencia de un fondo para la estabilización de la actividad institucional y del interés en preservar las actividades benéfico sociales, más necesarias que nunca en periodos de dificultad, los fondos a ellas dedicadas se han visto fuertemente reducidos en los últimos cuatro años, retrocediendo por debajo de los mil millones de euros, un nivel equiparable al del año 2001.

Figura 5

Fondos dedicados a actividades institucionales por las FOB en millones de euros, 1993-2012

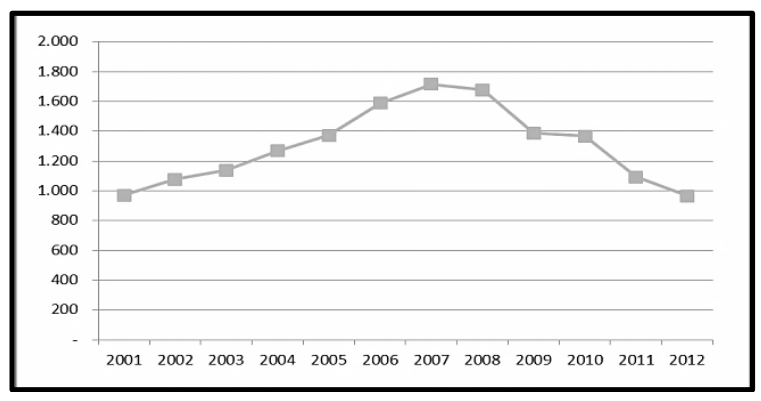

Fuente: Elaboración propia a partir de ACRI, Rapporto Annuale, varios números. 
La distribución de fondos por sectores beneficiarios durante la última década aparece en la Tabla $4^{43}$. Desde su origen las FOB han tendido a concentrar su actividad institucional en unos cuantos sectores y a dedicar a ellos la mayor parte de los fondos distribuidos. La tabla revela que los siete sectores principales de los trece enumerados -los mismos desde el principio aunque en distinto orden- han recibido cada año aproximadamente el $95 \%$ de los fondos. Los cinco primeros han absorbido anualmente más de las tres cuartas partes del total y a los tres primeros se ha destinado siempre más de la mitad de los recursos disponibles.

\section{Tabla 4}

Distribución de los fondos destinados a actividades institucionales por sectores beneficiarios

\begin{tabular}{|c|c|c|c|c|c|c|c|c|c|c|c|c|c|c|}
\hline \multirow[b]{3}{*}{ Sectores $^{1}$} & \multicolumn{4}{|c|}{2012} & \multirow{2}{*}{\multicolumn{2}{|c|}{$\frac{2010}{\text { Importe }}$}} & \multirow{2}{*}{\multicolumn{2}{|c|}{$\frac{2008}{\text { Importe }}$}} & \multirow{2}{*}{\multicolumn{2}{|c|}{$\frac{2006}{\text { Importe }}$}} & \multirow{2}{*}{\multicolumn{2}{|c|}{$\frac{2004}{\text { Importe }}$}} & \multirow{2}{*}{\multicolumn{2}{|c|}{$\frac{2002}{\text { Importe }}$}} \\
\hline & \multicolumn{2}{|c|}{ Actuaciones } & \multicolumn{2}{|c|}{ Importe } & & & & & & & & & & \\
\hline & $\mathbf{N}^{0}$ & $\%$ & M de $€$ & $\%$ & M de $€$ & $\%$ & M de $€$ & $\%$ & M de $€$ & $\%$ & M de $€$ & $\%$ & M de $€$ & $\%$ \\
\hline 1. Arte, actividades y bienes culturales & 7872 & 35.5 & 305.3 & 31.6 & 413.0 & 30.2 & 513.1 & 30.6 & 487.8 & 30.7 & 408.1 & 32.2 & 311.3 & 28.9 \\
\hline 2. Educación, instrucción y formación & 3427 & 15.4 & 144.8 & 15 & 148.2 & 10.8 & 216.9 & 12.9 & 184.9 & 11.6 & 150 & 11.8 & 176.9 & 16.4 \\
\hline 3. Asistencia social & 2712 & 12.2 & 124.5 & 12.9 & 174.8 & 12.8 & 151.1 & 9 & 146.5 & 9.2 & 135.5 & 10.7 & 134.5 & 12.5 \\
\hline 4. Investigación & 1244 & 5.6 & 118.5 & 12.3 & 171.6 & 12.6 & 251.6 & 15 & 171.1 & 10.8 & 131.2 & 10.3 & 96.2 & 8.9 \\
\hline 5. Voluntariado, filantropía y beneficencia & 2682 & 12.1 & 117.3 & 12.1 & 130.7 & 9.6 & 170.4 & 10.2 & 267.5 & 16.8 & 167.3 & 13.2 & 129.5 & 12 \\
\hline 6. Desarrollo local & 1379 & 6.2 & 55.4 & 5.7 & 124.5 & 9.1 & 161.1 & 9.6 & 98.9 & 6.2 & 78.5 & 6.2 & 72.9 & 6.8 \\
\hline 7. Salud pública & 1129 & 5.1 & 54.6 & 5.7 & 114.2 & 8.4 & 122.2 & 7.3 & 157.7 & 9.9 & 145.6 & 11.5 & 112.5 & 10.4 \\
\hline 8. Protección y calidad ambiental & 354 & 1.6 & 18.4 & 1.9 & 33.8 & 2.5 & 41.3 & 2.5 & 25.2 & 1.6 & 21.7 & 1.7 & 23.4 & 2.2 \\
\hline 9. Familia y valores relacionados2 & 218 & 1 & 17.4 & 1.8 & 32.3 & 2.4 & 15.3 & 0.9 & 10.7 & 0.7 & 10.6 & 0.8 & - & - \\
\hline 10. Ocio y deporte & 1117 & 4.9 & 8.6 & 0.9 & 21.4 & 1.6 & 28.4 & 1.7 & 33.7 & 2.1 & 15.7 & 1.2 & 14 & 1.3 \\
\hline 11.Prevención de la criminalidad y seguridad pública2 & 17 & 0.1 & 0.4 & 0.1 & 0.1 & 0 & 0.1 & 0 & 0.3 & 0 & 0.7 & 0.1 & - & - \\
\hline 12. Derechos civiles3 & 35 & 0.2 & 0.3 & 0 & 1.1 & 0.1 & 1.4 & 0.1 & 2.6 & 0.2 & 0.1 & 0 & 0.2 & 0 \\
\hline 13. Religión y desarrollo espiritual3 & 18 & 0.1 & 0.2 & 0 & 0.7 & 0 & 3.2 & 0.2 & 1.2 & 0.1 & 2.9 & 0.2 & 1.9 & 0.2 \\
\hline 14. Seguridad alimentaria y agricultura de calidad $^{6}$ & & & & & - & - & 0.5 & 0 & - & - & - & - & - & - \\
\hline 15. Actividad internacional ${ }^{4}$ & & & & & - & - & - & - & - & - & - & - & 3.5 & 0.3 \\
\hline TOTAL & 22204 & 100 & 965.8 & 100 & 1366.6 & 100 & 1676.7 & 100 & 1588.10 & 100 & 1267.8 & 100 & 1076.70 & 100 \\
\hline
\end{tabular}

1: La clasificación de sectores empleada por ACRI no coincide exactamente con la lista de "sectores admitidos" de la normativa aunque es coherente con ella.

2: Este sector se introduce en la parrilla a partir de 2004.

3: Aparece en la clasificación en el año 2001.

4: Este sector es introducido en el año 2001 y excluido a partir de 2004.

6: Este sector se introduce en la clasificación en 2008.

$M$ de $€$ : Millones de euros.

Fuente: ACRI.

El sector de Arte, actividades y bienes culturales siempre ha ocupado el primer lugar, habiendo recibido año a año casi una tercera parte de los fondos. En 2012 las fundaciones destinaron a este tipo de actividades 305,3 millones de euros través de 7.872 actuaciones. La Educación siempre se ha situado en los

${ }^{43}$ Aunque por razones de espacio la tabla solamente recoge el periodo 2002-2012, los comentarios se refieren al periodo 1993-2012. 
puestos cuarto a segundo, lugar éste que ha recuperado en el último año. El sector de Asistencia social ha recuperado posiciones en los tres últimos años, fenómeno que guarda relación con el papel que las FOB están jugando durante la crisis. El de Investigación ha ganado importancia a lo largo de la década al pasar de las posiciones quinta y sexta que ocupaba en la primera mitad hasta los puestos tercero y cuarto de los últimos años. El de Voluntariado ha perdido peso en los dos últimos años ya que se ha situado en los lugares quinto y sexto, cuando antes había estado en el segundo puesto en los años 2004-2006. Los sectores de Desarrollo local y Salud pública que se han ido alternando en el séptimo lugar de la tabla absorben en 2012 una cantidad de fondos equivalente y próxima al 6 por ciento del total de fondos comprometidos.

Entre el resto de los sectores, merece la pena destacar el de Ocio y deporte porque con menos del $1 \%$ del total de los fondos, 8,6 millones de euros, ha posibilitado un número de actuaciones equivalente al de sectores como Investigación, Desarrollo local o Salud Pública, lo que pone de manifiesto la capilaridad de este tipo de actividades que tienen una visibilidad social inmediata.

Dejando a un lado la importancia de la distribución de los fondos entre los distintos sectores beneficiarios, hay que tener presente que en 2012 el total de fondos distribuidos se reduce en un 11,6\% respecto al año anterior, continuando con la tendencia descendente iniciada en 2008, y que, por consiguiente, prácticamente todos los sectores han visto mermados los recursos recibidos.

La concentración sectorial de los recursos distribuidos por las FOB se mide a nivel individual mediante el grado de especialización. Así podemos decir que una fundación tiene un nivel de especialización alto si destina el $50 \%$ o más de sus recursos a un solo sector o más del $60 \%$ a dos sectores; un nivel medio si dedica al menos el $30 \%$ a un solo sector o el $40 \%$ o más a dos sectores; $y$, finalmente, el resto de las fundaciones son consideradas con un nivel bajo de especialización. Pues bien todas las fundaciones mantienen un nivel de especialización medio o alto acorde con una regulación que, para evitar una excesiva dispersión de sus actividades, impone la obligación de destinar al menos el 50 $\%$ de sus recursos disponibles a no más de cinco sectores relevantes elegidos de entre los sectores admitidos ${ }^{44}$. A lo largo de la década son mayoritarias las que mantienen una especialización elevada frente a las de especialización media. En 2012 pertenecen a cada categoría 47, 39 y 2 fundaciones respectivamente.

Los sujetos beneficiarios de las actividades benéfico-sociales de las FOB son instituciones públicas o entidades y organismos privados que operan establemente en el territorio con fines no lucrativos y de interés público; se convierten así en el instrumento a través del cual los recursos de las fundaciones se concretan en actividades y servicios para los ciudadanos de la comunidad. A lo

${ }^{44}$ Esta elección puede ser modificada por la fundación cada tres años. 
largo de la década (Figura 6), el sector privado ha ido recibiendo un porcentaje cada vez mayor del importe distribuido, confirmándose así que, inspiradas en el principio de subsidiariedad horizontal, las FOB han tendido a establecer vínculos preferentes con el sector privado social; fundaciones, asociaciones, organizaciones de voluntarios, cooperativas sociales y otros organismos privados, entre los que se cuentan las instituciones religiosas, son, por este orden, los beneficiarios que reciben mayores fondos. Por el contrario, los fondos canalizados a través de entidades públicas han ido perdiendo peso en términos relativos. Entre los beneficiarios públicos, los entes locales han sido interlocutores privilegiados seguidos de los entes públicos no territoriales que incluyen escuelas, universidades, estructuras sanitarias, instituciones de acogida y beneficencia, mientras que la administración central ocupa la última posición entre los sectores beneficiarios. En 2012 la horquilla entre receptores privados y públicos alcanza un máximo de 38 puntos porcentuales frente a los 16 del inicio del siglo.

Figura 6

Organizaciones beneficiarias de la actividad institucional de las fundaciones.

En porcentaje de los fondos distribuidos

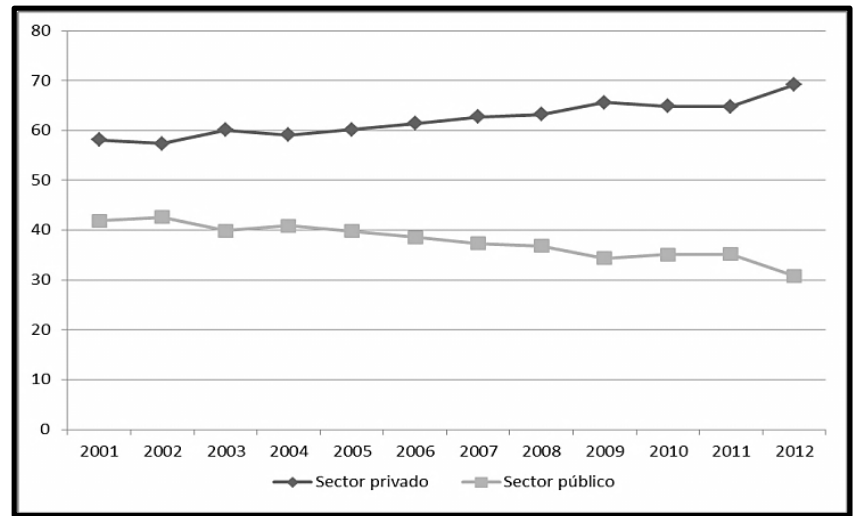

Nota: No se toman en cuenta las actuaciones por importe inferior a 5.000 euros.

Fuente: Elaboración propia a partir de ACRI, Rapporto annuale, varios números.

Una característica relevante de la forma en que se llevan a cabo las actividades institucionales de las fundaciones es el papel que éstas adoptan en su realización. Las FOB han optado preferentemente por la modalidad dotacional (granting) frente a la funcional (operating). El modelo granting se basa en la consecución de los fines institucionales mediante la entrega de contribuciones financieras a terceros, que ejecutan materialmente los proyectos de intervención. En el modelo funcional, por el contrario, es la propia fundación la que se implica en la realización directa de las iniciativas, gestionando, por ejemplo, 
una institución socio-sanitaria o un museo. Esta opción queda bastante clara en la Figura 7 que muestra cómo entre un $80 \%$ y un $90 \%$ de los recursos se aplican a través de subvenciones de obras y servicios, quedando tan solo un $10 \%$ para actuación directa de la fundación o financiación de empresas instrumentales.

Figura 7

Papel de las fundaciones en la realización de las obras benéfico sociales

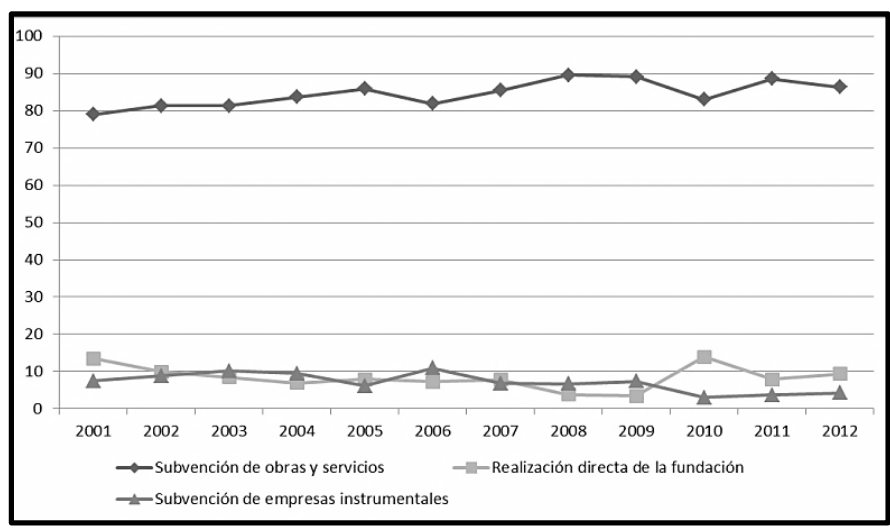

Fuente: Elaboración propia a partir de datos de ACRI, Rapporto annuale, varios años.

Figura 8

Distribución de los recursos según el origen de los proyectos

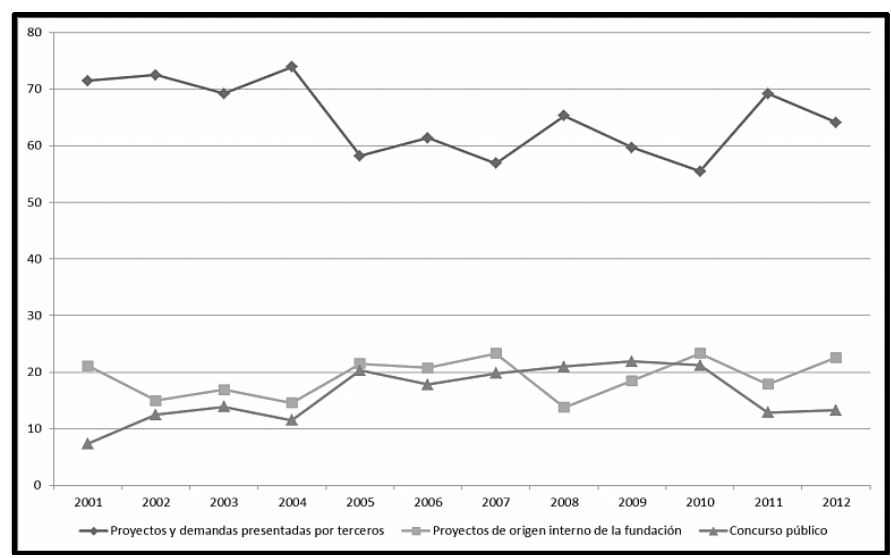

Fuente: ACRI, Informe Anual, Varios años.

En cuanto al origen de los proyectos (Figura 8), las propuestas de terceros, ideadas y desarrolladas íntegramente fuera de la fundación, son dominantes, 
absorbiendo entre un $60 \%$ y un $70 \%$ a lo largo de la última década. En cambio, la realización directa del proyecto por la fundación, oscila alrededor del $20 \%$ y otro tanto ocurre con la asignación de recursos mediante concursos, que representa una forma de actividad intermedia entre las otras dos.

\subsection{Localización geográfica de las actividades de las FOB}

La concentración de los recursos disponibles para el desarrollo de las actividades propias de las fundaciones es reflejo y consecuencia lógica de la concentración geográfica y patrimonial a que nos referíamos más arriba.

Tabla 5

Fondos distribuidos por grupos de fundaciones en \% sobre el total

\begin{tabular}{|c|c|c|c|c|c|c|c|}
\hline & & \multicolumn{2}{|c|}{2001} & \multicolumn{2}{|c|}{2006} & \multicolumn{2}{|c|}{2012} \\
\hline & $\begin{array}{c}\mathrm{N}^{\circ} \\
\text { FOB }\end{array}$ & $\begin{array}{c}\% \text { del } \\
\text { importe }\end{array}$ & $\begin{array}{c}\% \text { de } \\
\text { actuaciones }\end{array}$ & $\begin{array}{c}\text { \% del } \\
\text { importe }\end{array}$ & $\begin{array}{c}\% \text { de } \\
\text { actuaciones }\end{array}$ & $\begin{array}{c}\text { \% del } \\
\text { importe }\end{array}$ & $\begin{array}{c}\% \text { de } \\
\text { actuaciones }\end{array}$ \\
\hline \multicolumn{8}{|l|}{ Según la dimensión } \\
\hline Fundaciones Grandes & 18 & 79,7 & 46,9 & 81,1 & 43,4 & 75,2 & 41,8 \\
\hline Fundaciones Medio-grandes & 17 & 10,7 & 20,1 & 8,9 & 17,6 & 13,5 & 18,8 \\
\hline Fundaciones Medianas & 18 & 5,5 & 14,7 & 6,1 & 17,1 & 6,3 & 19,8 \\
\hline Fundaciones Medio-Pequeñas & 17 & 2,6 & 11,2 & 2,5 & 9,4 & 3,4 & 10,4 \\
\hline Fundaciones Pequeñas & 18 & 1,4 & 7,1 & 1,4 & 12,5 & 1,6 & 9,2 \\
\hline Sistema fundaciones & 88 & 100 & 100 & 100 & 100 & 100 & 100 \\
\hline \multicolumn{8}{|l|}{ Según la división geográfica } \\
\hline Noroeste & 17 & 28,9 & 30,4 & 36,6 & 33,6 & 42,9 & 34 \\
\hline Noreste & 29 & 41 & 38,2 & 33,3 & 32,8 & 30,3 & 31,5 \\
\hline Centro & 30 & 28,8 & 26,5 & 28,1 & 27 & 23 & 23,6 \\
\hline Sur e Islas & 12 & 1,3 & 4,8 & 2 & 6,6 & 3,8 & 10,9 \\
\hline
\end{tabular}

Fuente: ACRI, Rapporto Annuale, varios números.

En la Tabla 5 se observa que el quintil de fundaciones catalogadas como grandes concentró en 2012 más de tres cuartas partes de los recursos distribuidos y el $42 \%$ de las actuaciones. En el extremo opuesto, el quintil de fundaciones más pequeñas distribuyó tan solo el $1.6 \%$ de los fondos y realizó el $9.2 \%$ de las actuaciones. En cuanto a su concentración geográfica, en la región meridional e islas están radicadas sólo 12 fundaciones que, aunque constituyen un $13 \%$ del total, distribuyen únicamente el $3.8 \%$ de los fondos totales. Las del norte, en cambio, realizan dos terceras partes de las intervenciones a través de las que distribuyen el $73 \%$ de los fondos.

Desde su origen, las FOB se han caracterizado por estar muy enraizadas en el territorio en el que están establecidas de manera que sus actividades han tenido siempre un marcado carácter local. Es esta una característica que se ha mantenido a lo largo del tiempo con algunos matices. En los años previos a la crisis habían comenzado a tomar fuerza las actividades realizadas fuera de la región sede de la fundación hasta alcanzar un máximo de casi una quinta parte del total en 2005. Sin embargo, es preciso señalar que la crisis ha marcado un 
retraimiento de las actividades fundacionales a la propia región o provincia de manera que ambas rúbricas absorben en 2012 más del $90 \%$ de los fondos (Figura 9).

\section{Figura 9}

Localización de las actividades de las FOB

Reparto porcentual por zona geográfica de destino

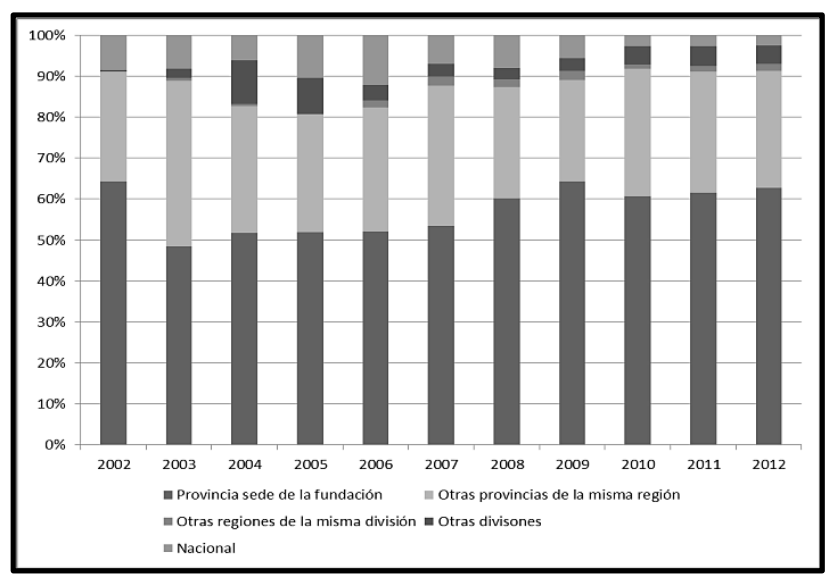

Fuente: Elaboración propia a partir de datos de ACRI, Rapporto annuale, varios años.

Si al hecho de que como acabamos de ver las FOB inyectan sus fondos preferentemente en su propia región, sumamos la circunstancia, comentada anteriormente, de que las fundaciones están localizadas preferentemente en el norte de Italia, es fácil deducir que serán estas regiones las que absorban un mayor porcentaje de los recursos distribuidos por estas entidades. Efectivamente, esto es lo que se refleja la Figura 10. En las regiones del norte se queda un $70 \%$ de los fondos, un peso que incluso ha aumentado en los últimos años como consecuencia del retraimiento mencionado, en un escenario de recursos disponibles menguantes en términos absolutos. Los fondos percibidos por la región centro oscilan alrededor del $25 \%$ y la del sur recibe menos recursos aun a pesar de los esfuerzos realizados por las FOB desde 2005 para reequilibrar el flujo de fondos hacia las regiones más pobres mediante la firma de un convenio de ACRI con el Tercer sector y el Voluntariado. Uno de los principales acuerdos fue la creación de la Fondazione per il Sud, dotada con un patrimonio inicial de 315 millones de euros y con aportaciones anuales durante los cinco años de vigencia de un acuerdo que se ha renovado en enero de 2010. 
Figura 10

Distribución porcentual de los recursos según el área de destino

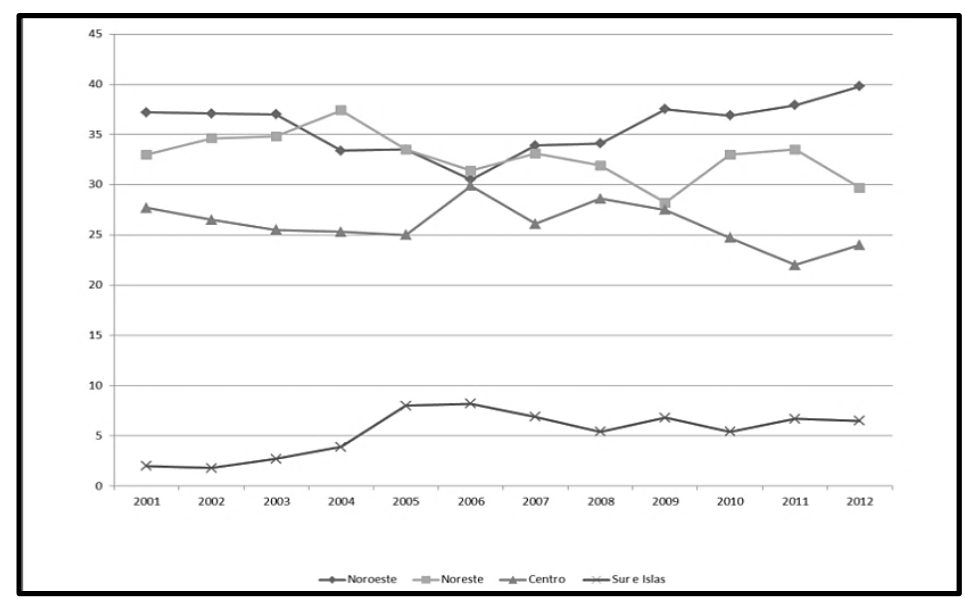

Fuente: ACRI, Rapporto annuale, varios años.

\subsection{Inversiones relacionadas con la misión de las fundaciones (IRM)}

En los últimos años, las FOB han impulsado las denominadas inversiones relacionadas con la misión (IRM). Se trata de un concepto ligado a lo que entendemos por inversión responsable. O sea, la selección de las inversiones no solo por los criterios económicos habituales (rendimiento, riesgo, liquidez, plazo, tratamiento fiscal), sino teniendo también en cuenta principios éticos y sociales y escogiendo aquellas que respondan a los fines de las fundaciones sin menoscabo de su rentabilidad. Ese impulso encuentra su respaldo en la propia regulación de 1999 en la que se ordena a las FOB administrar su patrimonio con prudencia y diversificación del riesgo pero donde también se dice que el patrimonio debe gestionarse para cumplir con las funciones institucionales y de desarrollo del territorio permitiendo incluso en ocasiones renunciar a una rentabilidad adecuada ${ }^{45}$. De esta forma, las fundaciones persiguen el cumplimiento de su misión no solo mediante la aplicación de los rendimientos de las inversiones a las actividades estatutarias sino mediante la propia selección de los sujetos y sectores destinatarios de dicha inversión.

Como se observa en la Tabla 6, las IRM de 2011 sumaron 3.533 millones de euros, lo que representa el 7,1\% del activo y el $8,2 \%$ del patrimonio de las FOB con un incremento respecto al año anterior del 2,7 \%. La adquisición de participaciones societarias es la forma de inversión elegida preferentemente por las FOB. Se trata de inversiones estables a largo plazo si bien están sujetas a las oscilaciones en las valoraciones de los mercados. La inversión a través de fon-

${ }^{45}$ Decreto legislativo 17 maggio 1999, n. 153, art. 5.1; art. 6.1; art. 7.1 y 3-bis. 
dos y otras actividades financieras (obligaciones y títulos de crédito), por el contrario, ha experimentado importantes incrementos nominales en los dos años observados.

\section{Tabla 6}

IRM de las fundaciones por sectores y forma de inversión (millones de euros)

\begin{tabular}{|c|c|c|c|c|c|c|c|c|c|}
\hline \multirow[b]{2}{*}{ Sectores } & \multicolumn{3}{|c|}{2011} & \multicolumn{3}{|c|}{2010} & \multicolumn{3}{|c|}{2009} \\
\hline & Total & $\begin{array}{l}\text { Participa- } \\
\text { ciones }\end{array}$ & $\begin{array}{l}\text { Fondos y } \\
\text { otras }\end{array}$ & Total & $\begin{array}{l}\text { Participa- } \\
\text { ciones }\end{array}$ & $\begin{array}{l}\text { Fondos } y \\
\text { otras }\end{array}$ & Total & $\begin{array}{l}\text { Participa- } \\
\text { ciones }\end{array}$ & $\begin{array}{c}\text { Fondos } y \\
\text { otras }\end{array}$ \\
\hline Desarrollo local & 3185 & 2608 & 577 & 3117 & 2653 & 464 & 2923 & 2626 & 297 \\
\hline $\begin{array}{l}\text { Arte, actividades y } \\
\text { bienes culturales }\end{array}$ & 135 & 124 & 11 & 128 & 117 & 11 & 114 & 84 & 30 \\
\hline Asistencia social & 73 & 12 & 61 & 46 & 20 & 26 & 37 & 15 & 22 \\
\hline $\begin{array}{l}\text { Educación, instrucción y } \\
\text { formación }\end{array}$ & 67 & 5 & 62 & 80 & 5 & 75 & 101 & 4 & 97 \\
\hline Investigación & 38 & 8 & 30 & 31 & 8 & 23 & 22 & 7 & 15 \\
\hline Salud pública & 21 & 12 & 9 & 24 & 12 & 12 & 26 & 12 & 14 \\
\hline Fondos éticos & 12 & - & 12 & 13 & - & 13 & 11 & - & 11 \\
\hline $\begin{array}{l}\text { Seguridad alimentaria y } \\
\text { agricultura de calidad }\end{array}$ & 2 & 2 & - & 2 & 2 & - & 2 & 2 & - \\
\hline Total & 3533 & 2771 & 762 & 3441 & 2817 & 624 & 3236 & 2750 & 486 \\
\hline
\end{tabular}

Esta información solamente se encuentra en los informes a partir 2009.

Fuente: ACRI, Informe Anual. Varios años.

Desde una perspectiva sectorial, el Desarrollo local absorbe el $90 \%$ del total de las IRM. En él se incluye la participación que 65 fundaciones mantienen en la Cassa Depositi i Prestiti (CDP) por valor de 1050 millones de euros. La operación se realizó en 2003 mediante suscripción del 30\% del capital social de la CPD cuando ésta se privatizó. De este modo, la CPD amplió su actividad tradicional -financiar a entes públicos locales y administraciones públicas- pasando también a fomentar actividades próximas a los objetivos de las FOB: desarrollo de las redes de infraestructuras del país, el apoyo a la PYME, investigación y transferencia de tecnología al mundo productivo.

Las fundaciones tienen también participaciones en sociedades con fuertes vínculos con el territorio de referencia y cruciales para impulsar el desarrollo económico: gestoras de autopistas, aeropuertos locales, empresas de capital mixto para la distribución de gas y electricidad y otras que promueven el tejido económico local mediante apoyo al turismo, artesanía, revalorización de áreas urbanas degradadas o gestión de ferias y mercados locales. Invierten asimismo en bancos que prestan dinero a una población que de otro modo no tendría acceso al crédito. Entre estos fondos participados cabe destacar dos: el Fondo F2 (infraestructuras y distribución de la energía y el Fondo Microfinanza 1.

El sector de Arte, actividades y bienes culturales incluye las inversiones realizadas en una treintena sociedades cuyas actividades van desde la industria editorial a la realización de obras teatrales y musicales. Dentro de la partida 
Asistencia social tienen particular relevancia las inversiones relacionadas con el apoyo a las viviendas sociales ya sea mediante participaciones societarias o fondos de inversión. La Investigación abarca tanto las participaciones directas e indirectas en sociedades del sector de la biotecnología, de las ciencias de la vida y de otras áreas con alto contenido innovador como la transferencia de I+D a la industria.

\section{CONCLUSIONES}

Las fundaciones de origen bancario italianas surgieron como resultado del proceso de restructuración bancaria emprendido en 1990 mediante el denominado conferimento: la entidad de crédito aportaba el negocio financiero a una $S p A$ a cambio de la titularidad de las acciones y conservaba las finalidades de carácter benéfico-social.

La reforma fue fundamental para la restructuración del sector bancario porque al adoptar las entidades la forma jurídica de sociedades por acciones lograron ser más reconocibles por los inversores, impulsar la captación de recursos propios y también facilitar el proceso de fusiones y adquisiciones necesario para conseguir el tamaño medio adecuado para competir en un nuevo marco institucional caracterizado por la libertad de establecimiento en la UE y el modelo de banca universal. Las FOB han jugado un papel notorio en este proceso al permanecer primero como núcleo estable de accionistas mayoritarios y contribuir después a la restructuración del mapa bancario italiano y a la consolidación de grandes grupos financieros permaneciendo como inversores estables a largo plazo aunque separados de la gestión de la entidad bancaria. Cabe asimismo destacar en este sentido que durante la crisis financiera, las FOB han suscrito ampliaciones de capital que han reforzado la solvencia de las entidades y la estabilidad del conjunto del sistema bancario.

El sistema fundaciones está constituido por 88 entidades y se caracteriza por una elevada concentración geográfica y patrimonial heredada del mapa de entidades crediticias originarias. En el norte hay más fundaciones y también se asientan allí bastantes de las más grandes. Este hecho tiene su reflejo en la disponibilidad de fondos para actividades institucionales, que depende de las rentas obtenidas de la inversión del patrimonio, $\mathrm{y}$, dado que las actuaciones tienen un marcado carácter territorial, en el volumen de fondos empleado en cada división geográfica. Este desequilibrio permanece si bien las fundaciones tratan de corregirlo mediante iniciativas como la Fondazione per il Sud.

Las fundaciones cuentan con un gran patrimonio: 50.000 millones de euros en 2010 -el doble de su patrimonio inicial-, si bien es cierto que la crisis lo ha reducido en 2012 hasta 42.000 millones. Está constituido principalmente por tres partidas: a) participación en las sociedades cesionarias; b) participación en 
otras sociedades y en instrumentales y c) inversión en instrumentos financieros a distintos plazos.

Las fundaciones dedican a la actividad institucional en los sectores admitidos los ingresos que obtienen de sus inversiones una vez deducidos los gastos e impuestos y apartadas las dotaciones a reservas obligatorias y voluntarias. Estos recursos alcanzaron su máximo en 2007 con 1.700 millones de euros, aunque como consecuencia de la crisis financiera su importe se ha reducido en los últimos años hasta bajar de los 1.000 millones de 2012. En el periodo 2001-2012 realizaron actuaciones por importe de 15.600 millones de euros, una media anual de 1.300 millones.

Por normativa y vocación, concentran su atención en unos pocos sectores. Siete de ellos captan tradicionalmente el $95 \%$ de los recursos dedicados a la actividad institucional: arte, actividades y bienes culturales; asistencia social; investigación; educación, instrucción y formación; voluntariado, filantropía y beneficencia; desarrollo local y salud pública. Estos sectores recibieron en 2012 algo más de 900 millones de euros. Cabe destacar finalmente que en los últimos años el sistema FOB ha prestado atención creciente a que sus inversiones estén relacionadas con su misión, contribuyendo de este modo a una mejor consecución de sus fines y un mayor alcance de sus donaciones.

La reestructuración del sector de cajas de ahorro españolas se ha producido en un contexto muy diferente al del conferimento. La crisis financiera internacional y el lastre generado por el estallido de la burbuja inmobiliaria han hecho que las cajas españolas afronten una transformación que conjuga una operación de saneamiento, un cambio en la forma de desarrollar la actividad financiera y un nuevo modelo de obra benéfico-social. La interacción de estos tres factores ha condicionado los ritmos y la transformación de las entidades y su orientación de cara al futuro.

La reestructuración de las cajas ha conllevado una no despreciable disminución del tamaño del sector ya se mida éste en volumen de activos, oficinas o empleados. La práctica totalidad de las cajas han transferido su negocio financiero a bancos creados ad hoc, conservando la gestión de la obra social como cajas o fundaciones de carácter especial ${ }^{46}$.

La todavía no aprobada ley de cajas de ahorros y fundaciones bancarias constituirá la última pieza de la reforma financiera. Permitirá la continuidad del modelo de cajas de ahorros, pero devolviéndolas a sus orígenes, esto es, poniendo límites estrictos a sus posibilidades operativas, a su tamaño y a su ámbito de actuación.

${ }^{46}$ Véase Climent Serrano (2012) para un análisis comparado de la gestión de bancos y cajas de ahorros en los años previos a la crisis, que justifica a juicio del autor la bancarización de éstas últimas. 
Las cajas que ejercen indirectamente la actividad y las fundaciones de carácter especial deberán transformarse en fundaciones bancarias u ordinarias. Serán fundaciones bancarias las que mantengan una participación superior al 10 por ciento del capital o de los derechos de voto de una entidad de crédito. Si dicha participación superase el 30 por ciento o lo fuera de control deberá presentarse un plan financiero en el que se detalle cómo hará frente la fundación a las posibles necesidades de capital de la entidad. Para el caso en el que la participación supere el 50 por ciento se exigirá además la elaboración de un plan de diversificación y la constitución de un fondo de reserva para hacer frente a posibles necesidades de recursos propios de la entidad participada. Estas y otras medidas pretenden pues disuadir a las fundaciones de mantener una participación mayoritaria en la entidad.

En cuanto al régimen de gobierno de las fundaciones, la nueva ley limita la participación de administraciones públicas y entidades y corporaciones de derecho público en los órganos de gobierno a un máximo del 25 por ciento. También se establece un régimen de incompatibilidades entre patronos de la fundación y consejeros del banco orientado a separar la gestión de ambas entidades.

Cuando la ley se aplique, se constituirán 34 fundaciones de las que, a tenor de los porcentajes arriba citados, no más de 9 podrán aspirar a la calificación de bancarias. Del resto, un buen número carece de paquete accionarial de las entidades cesionarias por tratarse de entidades intervenidas y cuyo capital quedó en su totalidad en manos del FROB. Así pues el sector de fundaciones bancarias nace a nuestro juicio debilitado y ésta es una de las razones por las que tenemos previsto estudiar su desenvolvimiento tras la aplicación de la nueva ley.

En Italia, el conferimento se desarrolló de modo gradual, lo que permitió avanzar de manera pausada, analizando e incluso enmendando las decisiones. En España, las circunstancias propias de la crisis y la difícil situación de algunas entidades han obligado a avanzar mucho más rápido, lo que ha limitado la posibilidad de corregir las decisiones adoptadas. Ello no obstante, la experiencia italiana puede ser una referencia.

\section{REFERENCIAS BIBLIOGRÁFICAS}

ACRI (varios años). Rapporto Annuale sulle Fondazioni di Origine Bancaria, ACRI, Roma, Recuperados en http://www.acri.it/17_ann/17_ann0049.asp 1 de enero de 2013.

AYADI, R. Y OTROS (2009). "Análisis por país: privatización de las cajas de ahorros italianas" en Diversidad en el sector bancario europeo. La actividad y el papel de las cajas de ahorros, FUNCAS, págs 159-177. 
BISONI C. Y STEFANO C. (2001). "Un análisis económico de las cajas de ahorro italianas", Perspectivas del Sistema Financiero, $n^{\circ} 73$, págs. 67-86.

CARLETTI, E. Y OTROS (2005). "The Privatization of Italian Banks - A Role Model for Germany?, Vierteljafrshefte zur Wirtschaftsforschung 74, 4, págs 32-50.

CLIMENT SERRANO, S. (2012). "La caída de las cajas de ahorros españolas. Cuestión de rentabilidad, tamaño y estructura de propiedad", Estudios de Economía Aplicada, Vol. 30-2 págs-. 1-26.

DE LA HUCHA CELADOR, F. (1991). "La reforma de las cajas de ahorros italianas", Papeles de Economía Española, n 46, 1991, págs 149-161.

DE LA HUCHA CELADOR, F. (1995). "La reforma de las cajas de ahorros italianas. De la ley Amato a la directiva Dini", Cuadernos de Información Económica, octubre, $\mathrm{n}^{\circ}$ 103, págs 50-65.

ROJO ÁLVAREZ-MANZANEDA, R. (2003). Las fundaciones bancarias: de cajas de ahorro a sociedades de capital. La experiencia italiana, Editorial Universidad de Granada, 294 págs.

SEVILLA, M.; PARDO, G.; Y TORREGROSA, T. "La reforma de las Cajas de Ahorro y la cuestión del crédito a la economía española" en Anales del XXV Congreso Internacional de Economía Aplicada ASEPELT, Santander, 8-11 de Junio de 2011.

\section{FUENTES}

Associazione di Fondazioni e di Casse di Risparmio Spa (ACRI): www.acri.it

Gazzetta Ufficiale della Repubblica Italiana: www.gazzettaufficiale.it

Senado español: www.senado.es

\section{REFERENCIAS LEGISLATIVAS}

Proyecto de Ley de cajas de ahorros y fundaciones bancarias, Boletín oficial de las Cortes Generales, Senado, $\mathrm{n}^{\circ} 260,7 / 11 / 2013$, págs. 37-71). Recuperado en http://www.senado.es/web/actividadparlamentaria/actualidad/leyes/entramitacion/ind ex.html el 6 de octubre de 2013.

Legge 30 luglio 1990, n. 128 Disposizioni in materia di ristrutturazione e integrazione patrimoniale degli istituti de credito di diritto pubblico (Gazzetta Ufficiale n.182 del 68-1990). Recuperado en www.gazzettaufficiale.it

Decreto legislativo 20 novembre 1990, $n$. 356. Disposizioni per la ristrutturazione e per la disciplina del grupo creditizio (Gazzetta Ufficiale n. 282 del 3-12-1990). Recuperado en www.gazzettaufficiale.it

Decreto legislativo 1 settembre 1993, n. 385, Testo unico delle leggi in materia bancaria e creditizia (Gazzetta Ufficiale n.230 del 30-9-1993 - Suppl. Ordinario n. 92 ) Recuperado en www.gazzettaufficiale.it

Legge 30 luglio 1994, n. 474. Conversione in legge, con modificazioni, del decreto-legge 31 maggio 1994, n. 332, recante norme per l'accelerazione delle procedure di dismissione di partecipazioni dello Stato e degli enti pubblici in societa' per azioni (Gazzetta Ufficiale n. 177 del 30-7-1994). Recuperado en www.gazzettaufficiale.it 
